\title{
Pre-dicting post-ligation syndrome
}

\author{
Shahab Noori, MD, MS, CBTI, ${ }^{\mathrm{a}, \mathrm{b}}$ and S. Ram Kumar, MD, PhD, FACS ${ }^{\mathrm{c}, \mathrm{d}}$
}

From the ${ }^{\mathrm{a}}$ Fetal and Neonatal Institute and ${ }^{\mathrm{c}}$ Heart Institute, Children's Hospital of Los Angeles; ${ }^{\mathrm{b}}$ Division of Neonatology, Department of Pediatrics, and ${ }^{\mathrm{d} D i v i s i o n}$ of Cardiac Surgery, Department of Surgery, Keck School of Medicine of University of Southern California, Los Angeles, Calif.

Disclosures: Authors have nothing to disclose with regard to commercial support.

Received for publication Aug 10, 2017; accepted for publication Aug 19, 2017; available ahead of print Sept 26, 2017.

Address for reprints: S. Ram Kumar, MD, PhD, FACS, Assistant Professor of Surgery and Pediatrics, Children's Hospital, Los Angeles, 4650 Sunset Blvd, Mailstop 66, Los Angeles, CA 90027 (E-mail: rsubramanyan@ chla. usc.edu).

J Thorac Cardiovasc Surg 2017;154:2060-1

$0022-5223 / \$ 36.00$

Copyright (C) 2017 by The American Association for Thoracic Surgery

http://dx.doi.org/10.1016/j.jtcvs.2017.08.048

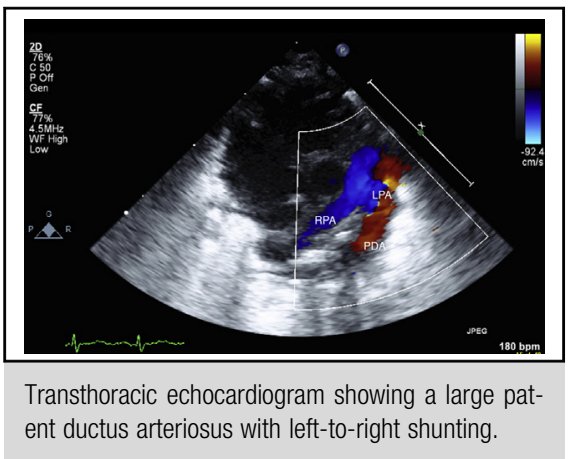

Management of a patent ductus arteriosus (PDA; Figure 1) in the preterm infant has become increasingly controversial during the last decade, largely due to the lack of randomized trials prospectively evaluating various treatment options. The growing uncertainty regarding the beneficial effects of medical treatment and percutaneous or surgical closure of PDA, combined with the potential side effects, has resulted in the adaptation of a more selective approach by most neonatologists. ${ }^{1}$ There is an urgent need to identify patients with hemodynamically significant PDA who are most likely to benefit from PDA closure that can be accomplished with a favorable morbidity profile.

About $10 \%$ to $45 \%$ of preterm infants undergoing surgical ligation of the PDA have postligation hemodynamic instability, which could potentially affect the long-term outcome of this vulnerable population. The mechanisms of postligation hemodynamic instability are complex and likely involve both myocardial dysfunction and vascular tone dysregulation. ${ }^{2-4}$ Information on preoperative factors that can predict postligation cardiovascular compromise, however, is scarce. In this issue of the Journal, Gray and colleagues ${ }^{5}$ used novel echocardiographic indices obtained before PDA ligation to predict which preterm infants would have postligation syndrome, as defined by a vasoactive inotropic score (VIS) of at least 20. They used left ventricular end-systolic elastance $\left(E_{e s}\right)$ and arterial elastance $\left(E_{a}\right)$ as measures of cardiac contractility and afterload. Although $\mathrm{E}_{\mathrm{es}}$ and $\mathrm{E}_{\mathrm{a}}$ were not different between patients with VIS less than 20 and 20 or greater, in multiple regression analyses higher $\mathrm{E}_{\mathrm{es}}$ and lower $\mathrm{E}_{\mathrm{a}}$ were associated with VIS of 20 or greater. Gray and colleagues ${ }^{5}$ speculate that higher contractility in the setting of lower afterload represents inappropriate ventriculoarterial coupling that does not respond favorably to acute changes in loading conditions such as those imposed by surgical duct ligation. They further suggest that by using a cutoff of $\mathrm{E}_{\mathrm{a}} / \mathrm{E}_{\text {es }}$ greater than 0.78 , one can safely identify patients at low risk for cardiovascular compromise after duct ligation. It is interesting that in their

analysis, $E_{\mathrm{a}} / \mathrm{E}_{\mathrm{es}}$ (calculated as end-systolic volume/stroke volume) was a better predictor of postligation syndrome, whereas the mathematically closely related ejection fraction (stroke volume/end-diastolic volume), which is easily measured and better understood, was not.

The search for noninvasive preoperative predictors of postligation syndrome is a valid exercise. Although the study by Gray and colleagues ${ }^{5}$ makes inroads by using these novel echocardiographic measures, it is premature to conclude that these data would change practice and drive the decision regarding which patients should undergo surgical PDA ligation. The echocardiographic data were obtained as long as 2 weeks before ligation and used single-beat estimations and single-time point noninvasive systolic blood pressure measurements without attention to concomitant inotropic support. The use of a VIS cutoff of 20 , which has not been evaluated in preterm infants undergoing nonbypass cardiac surgery, as a surrogate for postligation syndrome is entirely arbitrary. The receiver operator characteristic curves to predict VIS of 20 or greater with $\mathrm{E}_{\mathrm{a}}$ and $\mathrm{E}_{\mathrm{es}}$ are not discriminatory. In addition, in light of the absolute lack of difference in $\mathrm{E}_{\mathrm{es}}$ and $\mathrm{E}_{\mathrm{a}}$ between patients with VIS of less than 20 versus 20 or greater $(P>.7)$, their significance in predicting VIS of 20 or greater in a multiple regression analysis is cause for ponder.

It is unlikely that one more complex mathematical measurement is going to supplant the intelligence of bedside clinical acumen in PDA management. It is incremental knowledge gained from novel approaches such as that undertaken by Gray and colleagues, ${ }^{5}$ however, that allows us 


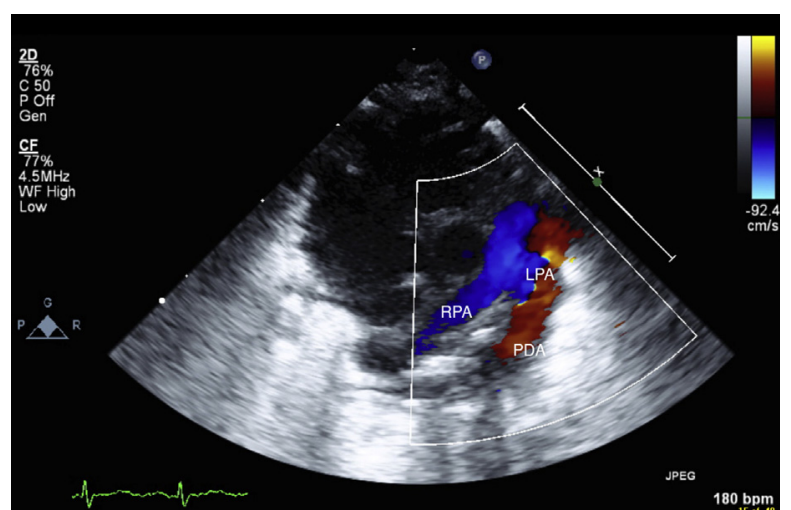

FIGURE 1. Transthoracic echocardiogram showing a large patent ductus arteriosus $(P D A)$ with left-to-right shunting. $L P A$, Left pulmonary artery; $R P A$, right pulmonary artery.

to arm ourselves with data that can be more predictive and discriminatory. If we are to achieve our goal of rationally balancing risks and benefits, we have to learn how better to use available data and technology to our benefit. The ultimate destination still lies ahead, but studies such as the one by Gray and colleagues ${ }^{5}$ suggest that we are well on our way.

\section{References}

1. Hagadorn JI, Brownell EA, Trzaski JM, Johnson KR, Lainwala S, Campbell BT, et al. Trends and variation in management and outcomes of very low-birth-weight infants with patent ductus arteriosus. Pediatr Res. 2016;80:785-92.

2. Noori S, Friedlich P, Seri I, Wong P. Changes in myocardial function and hemodynamics after ligation of the ductus arteriosus in preterm infants. $J$ Pediatr. 2007; 150:597-602.

3. McNamara PJ, Stewart L, Shivananda SP, Stephens D, Sehgal A. Patent ductus arteriosus ligation is associated with impaired left ventricular systolic performance in premature infants weighing less than 1000 g. J Thorac Cardiovasc Surg. 2010; 140:150-7. Erratum in: J Thorac Cardiovasc Surg. 2010;140:944.

4. Noori S, McNamara P, Jain A, Lavoie PM, Wickremasinghe A, Merritt TA, et al PDA Ligation/Hypotension Trial Investigators. Catecholamine-resistant hypotension and myocardial performance following patent ductus arteriosus ligation. $J$ Perinatol. 2015:35:123-7.

5. Gray MA, Graham EM, Atz AM, Bradley SM, Kavarana MN, Chowdhury SM. Preoperative echocardiographic measures of left ventricular mechanics are associated with postoperative vasoactive support in preterm infants undergoing patent ductus arteriosus ligation. J Thorac Cardiovasc Surg. 2017;154:2054-9. 